\title{
O CONCEITO DE GRANDE TEMPO E INTERPRETAÇÃO DE DISCURSOS
}

\author{
THE CONCEPT OF GREAT TIME AND \\ INTERPRETATION OF DISCOURSES
}

\section{Cláudio Primo Delanoy*}

Pontifícia Universidade Católica do Rio Grande do Sul, Porto Alegre, RS, Brasil

\begin{abstract}
Resumo: Este trabalho tem como tema interpretaçōes de discursos ao longo do tempo. Elegemos o Círculo de Bakhtin como base teórica porque sua concepção de linguagem envolve a natureza ideológica do signo lingústico a partir da interaçā̃o entre interlocutores situados social e historicamente. Bakhtin assume que as obras vivem no grande tempo e rompem as fronteiras de sua época. Temos como objetivos: (i) refletir sobre o conceito de grande tempo aplicado à interpretaçã̃o de discursos; (ii) discutir a importância do conhecimento cultural de produção do discurso para a sua interpretação; (iii) analisar como o distanciamento ideológico sócio-histórico e cultural colabora para a construção de novos sentidos. Analisaremos uma postagem em rede social relacionada ao conto Branca de Neve e um poema de Álvares de Azevedo. 0 método consiste na aplicacãoo de conceitos bakhtinianos aos enunciados. Como resultado, a interpretação envolve o posicionamento ideológico do leitor.
\end{abstract}

Palavras-chave: Círculo de Bakhtin; discurso; distanciamento; ideologia; literatura.

Abstract: The discourse reflects and refracts ideological values that characterize a perspective at the world. The interpretation of literary works also occurs in a similar way. The theme of this work is the interpretations of discourses over time. We chose the Bakhtin Circle as a theoretical basis due to its conception of language, which involves the ideological nature of the linguistic sign, based on the interaction between socially and historically situated interlocutors. Bakhtin assumes that discourses live in great time and break the boundaries of his time. Our aims are: (i) to reflect on the concept of great time applied to the interpretation of discourses; (ii) to discuss the importance of the cultural knowledge of the discourse production for its interpretation; (iii) to analyze how the socio-historical and cultural ideological distance collaborates for the construction of new meanings. We will analyze a social network post related to the tale Snow White and the poem É ela! I É ela! É ela! É ela! by Álvares de Azevedo. The method consists of applying Bakhtinian concepts to the statements. The results show that interpretation involves not only the perception of voices from the context of production of the works, but also the ideological positioning of the reader.

Keywords: Bakhtin Circle; discourse; Detachment; Ideology; literature.

* Professor doutor da Pontifícia Universidade Católica do Rio Grande do Sul - PUCRS, Porto Alegre, RS, Brasil; https://orcid.org/0000-0002-8015-5349; claudio.delanoy@pucrs.br

http://dx.doi.org/10.11606/issn.2236-4242.v33i3p153-174

Todo conteúdo da Linha D'Água está sob Licença Creative Commons Attribution-NonCommercial 4.0 International License 
Linha D’Água (Online), São Paulo, v. 33, n. 3, p. 153-174, set.-dez. 2020

\section{Introdução}

Interpretar o sentido de um discurso é sempre desafiador. A linguagem não se revela transparente, pois é da natureza do signo linguístico a não correspondência imediata com os objetos do mundo. Desse modo, linguistas semanticistas e analistas do discurso pesquisam continuamente esse grande desafio que é construir sentido. É neste grande contexto de pesquisa que se insere este trabalho ${ }^{1}$. Buscamos aqui tratar dos sentidos de discursos por meio do referencial teórico do Círculo de Bakhtin, mas a partir de um olhar específico: os diversos sentidos de uma obra ao longo do tempo. Para Bakhtin, um discurso não se fecha em si mesmo, pois pode revelar novos sentidos ao entrar no que denominou grande tempo, quando analisado sob circunstâncias culturais e sócio-históricas diversas.

Neste âmbito, propomos como objetivos: (i) refletir sobre o conceito de grande tempo aplicado à interpretação de discursos; (ii) discutir a importância do conhecimento do contexto cultural de produção do discurso para a sua interpretação; e (iii) analisar como o distanciamento ideológico sócio-histórico e cultural colabora para a construção de novos sentidos. Para alcançarmos mais especificamente este último objetivo, vamos analisar dois discursos. O primeiro é uma postagem em rede social que põe lado a lado um quadrinho polêmico com o beijo entre dois super-heróis masculinos e a imagem do beijo clássico do Príncipe que desperta Branca de Neve de seu sono mortal. Será a interpretação desses beijos que vai nos interessar. Depois, analisaremos o poema de Álvares de Azevedo É ela! É ela! É ela! É ela!, no qual a ação do eu-lírico ao adentrar furtivamente no quarto da amada, enquanto ela dormia, pode suscitar interpretações distintas. Como método, fundamentamo-nos, conforme já referido, nas reflexões do Círculo de Bakhtin. O grupo de pensadores propõe que a linguagem tem uma natureza dialógica, quer dizer, um discurso nasce e de desenvolve sempre em contato com outro, com o discurso do outro. É somente neste contato que o sentido é construído. Tal concepção tem influência direta na interpretação da obra, pois pela relação feita com discursos

1 Este trabalho está vinculado ao grupo de pesquisa Discursos em Diálogo (PUCRS), certificado pelo $\mathrm{CNPq}$.

DELANOY, C. P. 0 conceito de grande tempo e interpretação de discursos 
Linha D’Água (Online), São Paulo, v. 33, n. 3, p. 153-174, set.-dez. 2020

diversos, o leitor poderá fazer distintas interpretações. Além disso, o deslocamento cultual, espacial e temporal do leitor igualmente contribuem para a abertura de possíveis e novos sentidos. Como metodologia desta pesquisa, analisaremos, então, os dois discursos anteriormente citados aplicando os conceitos bakhtinianos de dialogismo, valoração, compreensão responsiva ativa, grande tempo, que nos parecem mais produtivos aos nossos objetivos.

Este artigo está estruturado da seguinte maneira: primeiramente apresentaremos os conceitos básicos da teoria bakhtiniana relevantes aos nossos propósitos; após, a metodologia, com detalhamento do corpus e procedimentos de análise; em seguida, proporemos as análises dos dois discursos selecionados; e, por fim, exporemos nossas considerações. Seguimos, então, com algumas das reflexões do Círculo de Bakhtin.

\section{Fundamentação teórica}

O Círculo de Bakhtin, denominação atribuída ao grupo de intelectuais que se reuniu na Rússia entre 1919 e 1929, era constituído por membros de formações diversas, como filósofos, músicos e professores. Dentre eles, destacaram-se Valentin Volóchinov, Pável Medviédev e, sem dúvida, Mikhail Bakhtin. A formação multidisciplinar do grupo não impediu que Bakhtin e seus pares tivessem um interesse em comum: o debate de ideias sobre filosofia, literatura e linguagem. No âmbito das reflexões sobre a linguagem, tomaram-na em sua modalidade viva, dita linguagem em uso, contrapondo-se aos estudos estritamente formais ou subjetivistas das produções linguageiras. A leitura das obras do Círculo faz transparecer um fio condutor perpassando as reflexões, e esse meio comum foi o dialogismo.

O dialogismo, então, é o conceito de base de toda a teoria do Círculoº ${ }^{2}$ O dialogismo é definido como o princípio da linguagem segundo o qual toda produção de discursos se dá a partir de outros discursos, estabelecendo-se entre eles relações de sentido. O dialogismo é considerado como inerente à linguagem, quer dizer, é da própria natureza da linguagem ser dialógica. Tal propriedade vem da ideia de

2 Ao longo deste texto, também a referimos como teoria bakhtiniana, tomando as expressões como correferenciais.

DELANOY, C. P. 0 conceito de grande tempo e interpretação de discursos 
Linha D’Água (Online), São Paulo, v. 33, n. 3, p. 153-174, set.-dez. 2020

que todo enunciado, tomado como unidade mínima real de comunicação, é constituído por outros enunciados, mais ou menos aparentes. Dessa forma, um enunciado nunca é considerado em sua autossuficiência, mas um elo numa cadeia com outros enunciados. A ideia de diálogo vem da linguagem em uso, na perspectiva de que um enunciado é produzido como sendo uma resposta a outro enunciado, além de suscitar, por sua vez, outras respostas, ou seja, cada enunciado é parte de uma cadeia de enunciados outros com os quais travam relações de sentido.

Outra decorrência do conceito de dialogismo é seu caráter social. O discurso do locutor é sempre orientado a um interlocutor, mas não na condição de emissor e destinatário (lembrando aqui o esquema de comunicação proposto por Jakobson), pois a linguagem se dá na interação entre ambos. $O$ discurso nasce a partir dessa interação, a ponto de o outro influenciar o discurso do locutor, mais ou menos explicitamente. Por exemplo, o simples fato de um locutor dirigir-se a um interlocutor ocupante de posição mais alta hierarquicamente tende a fazer o locutor usar um registro mais formal da linguagem; ou quando esse mesmo locutor fala com um amigo ou familiar, seu enunciado tende a ser mais informal. Segundo Volóchinov:

Em sua essência, a palavra é um ato bilateral. Ela é determinada tanto por aquele de quem ela procede quanto por aquele para quem se dirige. Enquanto palavra, ela é justamente o produto das inter-relações do falante com o ouvinte. Toda palavra serve de expressão ao "um" em relação ao "outro". [...] A palavra é uma ponte que se liga ao eu e ao outro. Ela apoia uma das extremidades em mim e a outra no interlocutor. A palavra é o território comum entre o falante e o interlocutor. (VOLÓCHINOV, 2017, p. 205, grifos do autor).

A citação de Volóchinov esclarece o caráter social e dialógico da linguagem em seu uso real. Nesse âmbito de uso efetivo da linguagem, o Círculo concebe a palavra, na sua qualidade de signo, não como um elemento componente de um sistema abstrato, simplesmente, mas como um signo ideológico. Isso quer dizer que o signo não só reflete os objetos do mundo (no sentido de fazer-lhes referência, não como espelhamento), mas simultaneamente carrega um ponto de vista sobre tais objetos, ou seja, refrata uma realidade. O signo já vem habitado por avaliação, 
Linha D’Água (Online), São Paulo, v. 33, n. 3, p. 153-174, set.-dez. 2020

por uma valoração dirigida ao objeto. É neste sentido que o signo é ideológico. Nas palavras de Volóchinov:

Na realidade, nunca pronunciamos ou ouvimos palavras, mas ouvimos uma ver-
dade ou mentira, algo bom ou mal, relevante ou irrelevante, agradável ou desagra-
dável e assim por diante. A palavra está sempre repleta de conteúdo e de significação
ideológica ou cotidiana. É apenas essa palavra que compreendemos e respondemos,
que nos atinge por meio da ideologia ou do cotidiano. (VOLÓCHINOV, 2017,
p. 181 , grifos do autor).

Daí podemos concluir a impossibilidade da existência de neutralidade na linguagem. Toda produção de linguagem é ideológica. Claro que a língua, tomada enquanto sistema, oferece ao falante certo número de expressões de caráter mais neutro, geral, pelas quais o falante poderia buscar um afastamento de responsabilidade perante seu discurso (pensamos aqui na linguagem das notícias de jornal, em que um tom mais neutro, imparcial, é requerido, justamente para dar mais relevância aos ditos fatos do que a uma avaliação do jornalista). No entanto, a própria busca da neutralidade já consiste em um ato ideológico, o que confirma o signo ser ideológico.

Até aqui vimos dois conceitos: o dialogismo, propriedade da linguagem que explica a construção de discursos a partir de outros discursos e as relações de sentido entre eles; e o signo de caráter ideológico, que apreende a realidade sob uma dada perspectiva, uma dada valoração. Tais conceitos mostram-se úteis para explicarmos as diferentes leituras que um leitor pode fazer de uma obra, de acordo com a relação com outros discursos e sua avaliação motivada por distintas perspectivas ideológicas. No entanto, outro ainda se faz relevante: o de compreensão responsiva ativa, já que é disso que se trata quando lidamos com o leitor interagindo com uma obra.

Por compreensão responsiva ativa, explica-nos Volóchinov:

Toda verdadeira compreensão é ativa e possui um embrião de resposta. [...] Compreender um enunciado alheio significa orientar-se em relação a ele, encontrar para ele um lugar devido no contexto correspondente. Em cada palavra de um enunciado compreendido, acrescentamos como que uma camada de nossas palavras responsivas. (VOLÓCHINOV, 2017, p. 232). 
E ainda segue: "Toda compreensão é dialógica. A compreensão opõe-se ao enunciado, assim como uma réplica opõe-se a outra no diálogo." (VOLÓCHINOV, 2017, p. 232, grifos do autor). Logo, compreender um discurso significa, de certa forma, produzir uma resposta. Tal definição parece-nos intimamente relacionada aos conceitos de dialogismo e de signo ideológico, pois a compreensão vai configurar um diálogo entre a obra e a resposta que o leitor vai lhe dar. Ao mesmo tempo, essa resposta não se constitui de um simples reconhecimento dos signos ou de uma repetição, como se a compreensão fosse uma paráfrase. De fato, como as palavras/ signos são ideológicos, e a compreensão sendo um discurso formado por esses signos, não há como o leitor compreender uma obra sem posicionar-se de modo avaliativo. Temos, portanto, a compreensão responsiva ativa, ou seja, o leitor assume um papel ativo no processo de compreensão do discurso ao responder a ele. Resta-nos fazer ainda uma observação terminológica envolvendo a expressão interpretação.

No texto A ciência da literatura hoje (Resposta a uma pergunta da revista Novi Mir), o tradutor Paulo Bezerra, na nota número 5, explica-nos a escolha da palavra interpretação:

Minha opção por interpretação em vez de compreensão [...] deve-se ao peso da cultura que Bakhtin insere no processo de interpretação e ao seu caráter dialógico, que resulta no enriquecimento da obra interpretada. Ademais, em se tratando de literatura, considero interpretação um termo mais apropriado que compreensão. (BAKHTIN, 2017, p. 13).

Escolhemos manter a expressão compreensão responsiva ativa para nos referirmos ao conceito teórico. Porém, apoiando-nos na nota acima, usaremos daqui em diante o termo interpretação como uma atividade cultural para construção de sentidos. Nas palavras de Bakhtin: "Assim, a interpretação completa o texto: ela é ativa e criadora." (BAKHTIN, 2017, p. 35).

Dando continuidade aos conceitos do Círculo mais relevantes a este trabalho, passamos ao grande tempo. Bakhtin desenvolve o conceito de grande tempo, de modo mais apurado, no texto $A$ ciência da literatura hoje (Resposta a uma pergunta da revista Novi Mir) (BAKHTIN, 2017). Em uma reflexão bastante rica, o pensador russo responde à revista sobre o estado da ciência da literatura na época (o texto foi publicado 
Linha D’Água (Online), São Paulo, v. 33, n. 3, p. 153-174, set.-dez. 2020

originalmente em 1970). Bakhtin afirmou a grande potencialidade de estudos da ciência da literatura, no entanto tais pesquisas não alcançavam expressividade por falta da proposição de questões mais ousadas, da carência de métodos elaborados pela experiência e predominância de truísmos e chavões (BAKHTIN, 2017, p. 10).

$\mathrm{Na}$ continuação do texto, Bakhtin propõe duas tarefas diante da ciência da literatura: o estabelecimento do vínculo com a história da cultura e o não fechamento do fenômeno literário com a sua época de criação. No primeiro caso, afirma-nos o pensador que: "A literatura é parte inseparável da cultura, não pode ser entendida fora do contexto pleno de toda a cultura de uma época." (BAKHTIN, 2017 , p. 11). Critica a ligação estreita dos estudos literários com fatores socioeconômicos, deixando a cultura de lado, quando, de fato, esses fatores agiriam sobre a cultura e essa, então, influenciaria a literatura. Sem tal vínculo, a literatura reduz-se a superficialidades formais, como se lê em: "Sob semelhante enfoque [isolamento da obra quanto à cultura] é impossível penetrar nas profundezas das grandes obras, e a própria literatura começa a parecer algo pequeno e assunto desprovido de seriedade." (BAKHTIN, 2017, p. 12).

A segunda tarefa da ciência da literatura é desfazer a necessidade de fechar a obra literária à sua época de concepção: "Por hábito, procuramos explicar um escritor e suas obras precisamente a partir de sua atualidade e do passado imediato (habitualmente no âmbito de uma época como a entendemos.)" (BAKHTIN, 2017, p. 13). Tal postura, analisando a obra a partir do pequeno tempo, o tempo da escrita (BEZERRA, 2017, p. 86), impossibilita o aprofundamento de sentidos e a vida da obra no futuro, que é vista como um paradoxo: "As obras dissolvem as fronteiras da sua época, vivem nos séculos, isto é, no grande tempo, e além disso levam frequentemente (as grandes obras, sempre) uma vida mais intensa e plena do que em sua atualidade."(BAKHTIN, 2017, p. 14, grifos do autor). A explicação do paradoxo na vida futura das obras vem do enriquecimento de novos sentidos ao longo do tempo. Uma obra não acontece inteiramente no presente (de sua criação). Ela tem raízes no passado, do qual pode ser concebida como uma resposta, em termos dialógicos, e lança-se ao futuro, dentro da ideia de um enunciado suscitar respostas vindouras, quer dizer, construções de sentidos outros. Explica-nos Bakhtin: 
[...] se o significado de uma obra se reduzisse, por exemplo, ao seu papel na luta contra o feudalismo (é o que se costuma fazer na escola secundária em nosso país [Rússia]), semelhante obra deveria perder inteiramente o seu significado quando o feudalismo e seus remanescentes deixassem a vida, mas amiúde a obra ainda aumenta o seu significado, isto é, entra no grande tempo. (BAKHTIN, 2017, p. 14 , grifos do autor).

Explica-se, então, o paradoxo proposto. A obra vive nos séculos através dos novos sentidos, processo no qual a cultura tem grande papel, pois é por ela que a obra revelará sentidos latentes, potenciais, sempre no aguardo de um contexto cultural favorável para manifestar-se. Nas palavras de Bakhtin (2017, p. 15), hoje conhecemos mais de Shakespeare do que seus contemporâneos ou até mesmo ele próprio. Sentidos adormecem nas obras, esperando o solo apropriado para eclodir. Dessa forma, o tempo liberta o autor de sua época, e a ciência da literatura deve contemplar tal fato. A ciência da literatura deve considerar o grande tempo.

Com isso, concluímos a impossibilidade de fechamento de sentidos relacionados a um discurso. A interpretação criadora, conforme diz nosso autor, não renuncia a si mesma, nem ao seu lugar no tempo ou à sua cultura (BAKHTIN, 2017, p. 18). É o distanciamento do intérprete, em termos de tempo, de espaço, de cultura, a grande causa da interpretação criadora. Sentidos revelam-se ao contato com outros sentidos, e somente dessa maneira são construídos. É somente pelo olhar do outro, de outro tempo, de outra cultura, que sentidos potenciais se revelam, numa volta ao conceito de dialogismo como fenômeno inerente à linguagem. Em tal diálogo, a tensão é constitutiva do sentido, já que: "Nesse encontro dialógico de duas culturas, elas não se fundem nem se confundem; cada uma mantém a sua unidade e a sua integridade aberta, mas elas se enriquecem mutuamente." (BAKHTIN, 2017, p. 19, grifo do autor).

A reflexão bakhtiniana sobre o grande tempo, motivadora deste artigo, possibilita explicarmos como um leitor pode construir sentidos outros de uma obra, de um discurso. Ele mesmo pode perceber sentidos até então invisíveis a partir de posteriores leituras do mesmo enunciado, pois no leitor também age o distanciamento. A riqueza de sua cultura, nunca fechada em si mesma, abre horizontes, locais de interpretação, garantindo assim a vida sempre renovada de uma obra. 
Linha D’Água (Online), São Paulo, v. 33, n. 3, p. 153-174, set.-dez. 2020

Precisamente nesta pesquisa, vamos mostrar como o grande tempo age em dois discursos. Para tanto, vamos ver os passos seguidos para as análises.

\section{Metodologia}

Para respondermos aos objetivos deste trabalho, organizamos assim a metodologia: quanto ao corpus (seleção); quanto à fundamentação teórica da pesquisa; e quanto aos procedimentos de análise (categorias). O corpus selecionado constituise de dois discursos:

(1) Uma postagem na rede social Facebook do dia 12 de setembro de 2019, em que são apresentadas duas imagens lado a lado: (a) um quadrinho da revista Vingadores, a Cruzada das Crianças (Marvel, lançada no Brasil em 2016), de Allan Heinberg e ilustrada por Jim Cheung, em que dois personagens masculinos, os super-heróis Wiccano e Hulkling, trocam afetos e se beijam; e (b) uma imagem clássica da animação Branca de Neve e os Sete Anôes (Disney, 1937), em que o Príncipe beija Branca de Neve para despertá-la do sono mortal causado pela rainha malvada;

(2) O poema narrativo É ela! É ela! É ela! É ela! (1853), de Manoel Antônio Álvares de Azevedo, no qual o eu-lírico adentra os aposentos de sua amada enquanto ela dormia.

Ambos discursos foram selecionados por suscitarem interpretações distintas daquelas feitas originalmente, quer dizer, quando as interpretações das obras entram no grande tempo revelam novos sentidos. Embora sejam provenientes de esferas distintas, como a midiática (postagem em rede social) e a literária (poema), os discursos selecionados revelam a ação do grande tempo, mostrando-nos assim que as tensões entre sentidos provocadas pelo distanciamento cultural do leitor não se aplicam ao campo literário, exclusivamente, mas a qualquer esfera de atividade humana.

Elegemos as reflexões do Círculo de Bakhtin como fundamentação teórica porque sua concepção de linguagem envolve o discurso em sua materialidade viva, situado cultural, social e historicamente. E como tratamos aqui de interpretação, e 
Linha D’Água (Online), São Paulo, v. 33, n. 3, p. 153-174, set.-dez. 2020

não de decodificação, precisamos de um aporte teórico que nos auxilie a explicar como uma obra pode ter diversos sentidos ao longo do tempo.

O método consiste na aplicação de conceitos bakhtinianos aos enunciados, tais como: dialogismo, valoração, compreensão responsiva ativa, grande tempo, para a construção do sentido. Partimos da concepção de discurso como construção dialógica, da palavra enquanto signo ideológico, das ideologias presentes no discurso.

\section{Análises}

Começamos pela postagem do Facebook, reproduzida abaixo sob forma esquemática, e seguimos com o poema de Álvares de Azevedo.

Fig. 1: Postagem (esquemática) do Facebook

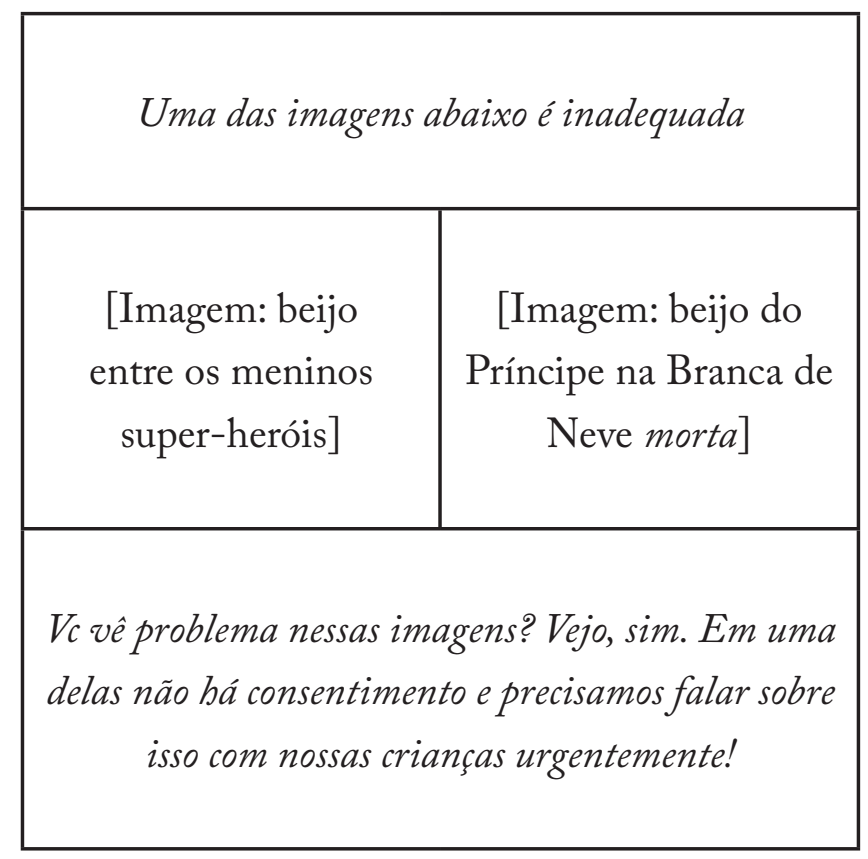

Fonte: o autor

A figura acima foi feita a partir da original ${ }^{3}$ postada na rede Facebook em 12 de setembro de 2019, que reproduz parte da revista de histórias em quadrinhos

3 A reprodução original da imagem não foi feita por dois motivos: (1) inacessibilidade da postagem na rede social atualmente, pois foi removida; (2) preservação dos direitos autorais das imagens. Como o interesse deste artigo não é a análise das imagens em si, mas unicamente

DELANOY, C. P. 0 conceito de grande tempo e interpretação de discursos 
Linha D'Água (Online), São Paulo, v. 33, n. 3, p. 153-174, set.-dez. 2020

Vingadores, a Cruzada das Crianças, de Allan Heinberg (Marvel) e uma cena clássica da animação Branca de Neve e os Sete Anões (Walt Disney Pictures). O diálogo entre as duas cenas se dá pelo tema beijo, com a diferença de acontecer entre dois personagens masculinos, no caso da revista da Marvel, e entre um masculino e outro feminino na animação da Disney. $\mathrm{O}$ enunciado postado na rede social combina as duas imagens com uma parte verbal, logo acima das figuras, com "Uma das imagens abaixo é inadequada", e abaixo, "Vc vê problema nessas imagens? Vejo, sim. Em uma delas não há consentimento e precisamos falar sobre isso com nossas crianças urgentemente!".

Essa postagem aconteceu após a realização da Bienal do Livro do Rio de Janeiro em 2019, que ganhou destaque na imprensa nacional pela atitude do prefeito do Rio na época, Marcelo Crivella, ao ter tentado recolher a referida revista da Marvel por divulgar, na sua concepção, conteúdo sexual para menores, e assim feriria o Estatuto da Criança e do Adolescente. A Prefeitura carioca chegou a enviar fiscais à feira, mas as edições já tinham esgotado. Tal atitude do prefeito foi tomada como censura tanto pela imprensa como nas redes sociais, principalmente por grupos LGBT.

A postagem é uma resposta ao discurso de Crivella, no sentido dialógico. Nosso intento é mostrar como um novo cenário cultural e sócio-histórico revela sentidos latentes em discursos, como preconiza Bakhtin e o Círculo. De início, vemos o enunciado "Uma das imagens abaixo é inadequada", que remete às figuras logo abaixo. $\mathrm{Na}$ esquerda, temos a imagem do beijo entre os dois heróis da Marvel, que gerou a indignação da prefeitura carioca; à direita, o beijo clássico entre o Príncipe e a Branca de Neve em sono mortal, que faz parte de nossa memória desde a infância. No contexto de inegável força cultural machista e homofóbica ainda presentes em nossa sociedade, embora haja a presença mais atuante de discursos defensores de grupos sociais inferiorizados tradicionalmente, como as mulheres, negros e homossexuais, a leitura do primeiro enunciado pode levar o leitor a levantar a hipótese de que a imagem inadequada seria a do beijo entre os dois meninos, em comparação com o beijo autorizado socialmente entre o Príncipe e a Branca de

o beijo entre os personagens e o texto verbal da postagem, acreditamos ser suficiente a referência às obras e a descrição apresentada. No entanto, em site de busca na internet, a figura pode ser encontrada pela entrada de <uma das imagens abaixo é inadequada>.

DELANOY, C. P. 0 conceito de grande tempo e interpretação de discursos 
Linha D'Água (Online), São Paulo, v. 33, n. 3, p. 153-174, set.-dez. 2020

Neve. Tal hipótese vem embasada justamente na cultura machista e homofóbica, que enxergará a inadequação naquilo que não faz parte dos modelos pré-aceitos de conduta afetiva entre duas pessoas. De acordo com a teoria bakhtiniana, a compreensão de um discurso se dá contextualmente, quer dizer, o leitor constrói sentidos a partir de uma visão ideológica, naquilo que chamou de compreensão responsiva ativa. Logo, muito provavelmente, é a partir de discursos já avaliados no contexto cultural machista que se dará a compreensão de outros discursos, comprovando-se assim o dialogismo como sendo inerente à construção do sentido. Portanto, explica-se a possível relação entre a imagem inadequada e o beijo entre os heróis, já que o beijo entre o Príncipe e a Branca de Neve é considerado normal.

Prosseguimos com a análise. Abaixo das imagens, segue o enunciado "Vc vê problema nessas imagens? Vejo, sim. Em uma delas não há consentimento e precisamos falar sobre isso com nossas crianças urgentemente!”. A pergunta é dirigida diretamente ao leitor, encenando o início de um diálogo. Há certa valoração de sentido por meio das palavras inadequada e problema relacionadas a uma das imagens, garantindo um tom avaliativo negativo, o que é confirmado pela afirmativa "Vejo, sim". Até então, se pensarmos na ideologia ainda machista de nossa sociedade, a referência parece ser ao beijo entre os meninos, conforme explicamos anteriormente. No entanto, a continuação do enunciado surpreende ao não confirmar tal hipótese, nem dar uma resposta objetiva, mas faz uma indicação: convida o leitor a perceber em uma delas um beijo não consentido, seguido da necessidade imperiosa de falar sobre o caso com o público infantil.

Ora, nesse momento o leitor é impelido a voltar às imagens e olhá-las de outro lugar, a partir de outra perspectiva. $\mathrm{O}$ enunciador da postagem oferece ao leitor uma nova contextualização, e a partir desse deslocamento pretende construir um novo sentido: não mais a perspectiva da polêmica do beijo gay na revista em quadrinhos, nem a do romântico conto da Branca de Neve, mas a do consentimento do ato afetivo. $\mathrm{O}$ autor da postagem convida o leitor a tomar distância, a deslocar-se de contextos ideológicos prévios e, a partir desse novo lugar, interpretar as imagens. Esse novo lugar é o da cultura de defesa do amor homoafetivo e da não submissão feminina aos desejos masculinos. Tal deslocamento faz-nos voltar não mais aos heróis da Marvel, que possivelmente tenha chamado mais a atenção do 
Linha D’Água (Online), São Paulo, v. 33, n. 3, p. 153-174, set.-dez. 2020

leitor pela sua transgressão, mas ao casal do conto de fadas. Surpreendentemente, ao recuperarmos a história da Branca de Neve, percebemos que o Príncipe beija a Princesa para despertá-la do feitiço mortal aplicado pela Rainha má, portanto, como Branca de Neve estava morta, o beijo do Príncipe não foi consentido pela Princesa. O foco, agora, passa da imagem supostamente ofensiva dos super-heróis àquela tida como autorizada pela ideologia machista dominante. Branca de Neve não tinha consentido o beijo, e esse fato ganha destaque ao servir para discussão com as crianças, num país onde se sabe que a violência sexual infantil tem grandes e graves proporções, bem como a de violência contra mulheres ${ }^{4}$.

Nosso interesse de pesquisa vem, então, explicar esse novo sentido revelado na obra Branca de Neve: a indicação de abuso por parte do Príncipe. Notamos que a cena na qual o herói salva a heroína da morte não foi modificada, mas reinterpretada devido ao deslocamento temporal, espacial e cultural do leitor, ou seja, a obra revelou sentidos latentes ao entrar no grande tempo. Uma cena que era e ainda é validada socialmente, vista como expressão do amor romântico entre os personagens do conto de fadas, passa a ganhar contornos de violência, de invasão de intimidade. O nascimento da nova interpretação tem origem na mudança de horizonte cultural, social, histórico e ideológico do leitor em diálogo com a contextualização de outra leitura da obra a partir do pequeno tempo, aquele da sua produção.

Porém, conforme nos escreve Bakhtin, as diversas interpretações de uma obra não se sobrepõem, não se misturam, mas entram em tensão. $O$ sentido da postagem evidencia tensões entre vários discursos ali mobilizados. $\mathrm{O}$ enunciado aproxima, articula, tensiona os discursos homofóbico, homoafetivo, o discurso romântico institucionalizado pela cultura, o discurso feminista. Como nos diz Volóchinov

4 Segundo o site do Ministério da Mulher, da Família e dos Direitos Humanos, dos 159 mil registros feitos pelo Disque Direitos Humanos ao longo de 2019, 86,8 mil são de violações de direitos de crianças ou adolescentes. A violência sexual infantil totalizou 17 mil ocorrências em 2019. Em matéria publicada pela Folha de São Paulo/ UOL, em 10/09/2019, foram contabilizados mais de 66 mil casos de violência sexual contra mulheres, o que corresponderia cerca de 180 estupros por dia. Veja em https://www.gov.br/mdh/pt-br/assuntos/noticias/2020-2/ maio/ministerio-divulga-dados-de-violencia-sexual-contra-criancas-e-adolescentes, Disponível em 19/06/2020;

https://www 1 .folha.uol.com.br/cotidiano/2019/09/brasil-registra-mais-de-180-estupros-pordia-numero-e-o-maior-desde-2009.shtml. Disponível em 19/06/2020.

DELANOY, C. P. 0 conceito de grande tempo e interpretação de discursos 
Linha D’Água (Online), São Paulo, v. 33, n. 3, p. 153-174, set.-dez. 2020

(2017, p. 140), “[...] toda palavra é um pequeno palco em que as ênfases sociais multidirecionadas se confrontam e entram em embate. Uma palavra nos lábios de um único indivíduo é um produto da interação viva das forças sociais". O sentido vem justamente do entrecruzamento dos discursos, e não de sobreposições ou apagamentos, conforme nos fundamenta o Círculo.

Não pretendemos condenar o conto da Branca de Neve pela nova leitura aqui proposta, mas sim pôr em diálogo as interpretações possíveis, discutir o embasamento discursivo, cultural de cada leitura. Como não é nosso propósito analisar o conto de fadas em si, acreditamos ter demonstrado, com tal exemplo, como um discurso pode, de fato, guardar sentidos latentes que esperam a ação do grande tempo para mostrar-se.

Passamos à segunda análise. Vamos ver como o grande tempo age sobre a interpretação do poema de Álvares de Azevedo (de 1853):

É ela! É ela! É ela! É ela!

É ela! é ela! — murmurei tremendo, e o eco ao longe murmurou - é ela! Eu a vi... minha fada aérea e pura a minha lavadeira na janela.

Dessas águas furtadas onde eu moro eu a vejo estendendo no telhado os vestidos de chita, as saias brancas; eu a vejo e suspiro enamorado!

Esta noite eu ousei mais atrevido, nas telhas que estalavam nos meus passos, ir espiar seu venturoso sono, vê-la mais bela de Morfeu nos braços!

Como dormia! que profundo sono!... Tinha na mão o ferro do engomado... Como roncava maviosa e pura!... Quase caí na rua desmaiado! 
Linha D’Água (Online), São Paulo, v. 33, n. 3, p. 153-174, set.-dez. 2020

Afastei a janela, entrei medroso...
Palpitava-lhe o seio adormecido...
Fui beijá-la... roubei do seio dela
um bilhete que estava ali metido...

Oh! decerto... (pensei) é doce página

onde a alma derramou gentis amores;

são versos dela... que amanhã decerto

ela me enviará cheios de flores...

Tremi de febre! Venturosa folha!

Quem pousasse contigo neste seio!

Como Otelo beijando a sua esposa,

eu beijei-a a tremer de devaneio...

É ela! é ela! — repeti tremendo;

mas cantou nesse instante uma coruja...

Abri cioso a página secreta...

Oh! meu Deus! era um rol de roupa suja!

Mas se Werther morreu por ver Carlota

Dando pão com manteiga às criancinhas,

Se achou-a assim tão bela... eu mais te adoro

Sonhando-te a lavar as camisinhas!

É ela! é ela, meu amor, minh'alma,

A Laura, a Beatriz que o céu revela...

É ela! é ela! - murmurei tremendo,

E o eco ao longe suspirou - é ela!

AZEVEDO, A. de., 1998.

Temos aqui o que podemos chamar de um poema narrativo. Em suas estrofes, canta o amor do eu-lírico pela sua amada, mas a partir de uma visão particular: ele a vê como fada e como lavadeira. Tais imagens oscilam ao longo do poema, encantando cada vez mais o poeta ${ }^{5}$. Após a contemplação distante a partir de sua

5 Neste trabalho, tomaremos os nomes "poeta" e "eu-lírico" como sinônimos, sem entrar em

DELANOY, C. P. 0 conceito de grande tempo e interpretação de discursos 
janela, o poeta decide atravessar o telhado que os separava, a vê dormindo e entra cuidadosamente ("entrei medroso") no quarto. É a interpretação de adentrar ao quarto que ganhará nossa atenção.

Antes, até chegarmos lá, precisamos resgatar o contexto no qual o poema foi criado. Manoel Antônio Álvares de Azevedo nasceu em São Paulo em 1831. Foi poeta do considerado período romântico de segunda geração, aqui no Brasil, denominado ultrarromantismo, na segunda metade do século XIX. Segundo Alfredo Bosi, em História concisa da literatura brasileira (BOSI, 2002, p. 110), em seus trabalhos havia a forte tendência para a evasão e para o sonho, provavelmente pela sua ligação com as ideias de Byron e com a vida boêmia. Encontramos nas produções ultrarromânticas temas recorrentes como a morte e a idealização da figura feminina, sempre inalcançável, diáfana, pura. Foi um período marcado pela predominância de temas oníricos, da negação da realidade, da fuga da vida concreta, da exploração da noite, do mundo ideal, dos exageros sentimentais, conforme nos diz Bosi:

[...] os nossos românticos exibem fundos traços de defesa e evasão, que os leva a posições regressivas: no plano da relação com o mundo (retorno à mãe natureza, refugio no passado, reinvenção do bom selvagem, exotismo) e no das relações com o próprio eu (abandono à solidão, ao sonho, ao devaneio, às demasias da imaginação e dos sentidos). (BOSI, 2002, p. 93).

Bosi também afirma que "o eu romântico, objetivamente incapaz de resolver os conflitos com a sociedade, lança-se à evasão” (BOSI, 2002, p. 93), por isso, frequentemente, prefere a noite ao dia, pois a luz do sol imporia a realidade ao sujeito. Nas trevas, haveria espaço para o inconsciente, para as fantasias.

Vemos algumas marcas dialógicas travadas com o romantismo em $E$ ela! É ela!..., seja pela caracterização da mulher, seja pela referência a outras obras de amor romântico. A mulher vista como fada, em suas características de aérea e pura (é inalcançável, idealizada), dorme profundamente (mais um elemento de distanciamento). Há referências explícitas a Otelo (de 1604), de Shakespeare (1906) (“Como Otelo beijando a sua esposa...") que, embora seja um autor do século XVI

detalhamentos de conceitos que no momento não pesam em nossa proposta.

DELANOY, C. P. 0 conceito de grande tempo e interpretação de discursos 
Linha D’Água (Online), São Paulo, v. 33, n. 3, p. 153-174, set.-dez. 2020

- XVII, portanto anterior ao ultrarromantismo, tem seu tema da impossibilidade da concretização do amor aqui lembrado); a Os sofrimentos do jovem Werther (de 1774), de Goethe (1998) ("Mas se Werther morreu por ver Carlota/ Dando pão com manteiga às criancinhas"), considerada a obra inaugural do ultrarromantismo na Europa, responsabilizada pelo aumento no número de suicídios no continente europeu (o mal do século); e a musas inspiradoras, Laura e Beatriz.

Álvares de Azevedo escreve É ela! É ela!... a partir desse horizonte ideológico, mas não para imobilizar seu discurso ultrarromântico: notamos um tom parodístico (e, podemos dizer, humorístico) no poema. Azevedo parece pôr em tensão dialógica o discurso da idealização romântica e o discurso da realidade concreta, visível, e localiza esse diálogo tenso da figura da amada: ela é fada e lavadeira, na visão do poeta, quase que simultaneamente. A figura de fada (é aérea, pura, escreve poemas de amor) está associada à idealização romântica, ao passo que a lavadeira (trabalha, dorme com o ferro de passar roupas na mão, ronca, guarda lista de roupas sujas) está relacionada à visão mais concreta do mundo. Pelo viés bakhtiniano, essa oposição entre discursos é constitutiva de sentido. Não há, assim como vimos na primeira análise, uma sobreposição de sentidos, mas relações tensas de sentido, via um dialogismo inerente a qualquer produção discursiva. $O$ discurso idealizado romântico nasce no âmbito do discurso mais objetivo, e vice-versa. Logo, vemos É ela! É ela!... como o resultado dessa tensão, que pode ser representativa da subjetividade do poeta, pois a alternância de como vê a amada mostra sua constituição também dialógica, como se vivesse numa fronteira entre ilusão e realidade, e, a partir dessa localização fluida, enxergasse o mundo. Assim, até aqui percebemos uma interpretação da obra considerando seu pequeno tempo, seu contexto social, cultural, ideológico.

Conforme dissemos anteriormente, nosso foco de análise é a interpretação do ato de o eu-lírico entrar no dormitório da amada, à noite, enquanto ela dorme. Seguindo as considerações feitas quanto ao pequeno tempo, o poeta age de acordo com suas perspectivas fronteiriças e oscilantes. Ele não se contém por estar a distância, então vai até a mulher, abre a janela do quarto e entra. Se consideramos tal atitude como uma tentativa de concretização de seu amor, o poeta nos frustra ao passar ao mundo da ilusão: no quarto, enquanto a mulher dormia, ele vai beijá-la, mas imediatamente se detém e prefere ler o bilhete que estava no peito da amada. 
Linha D'Água (Online), São Paulo, v. 33, n. 3, p. 153-174, set.-dez. 2020

Delira pensando serem "versos de amor" a ele dirigidos, mas, na verdade, ao ler percebe se tratar de um rol, uma lista de roupas. Ao pegar o papel, beija-o. Vemos que o pronome “-a" de "eu beijei-a a tremer de devaneio..." refere-se à folha de papel, referente sintático mais próximo sintaticamente, e não à mulher, o que confere a adesão ao discurso romântico, cujo amor não se concretiza, permanece na idealização. Portanto, o ato de entrar no quarto da mulher, contemplá-la, sem contato físico, está de acordo com o pensamento ultrarromântico. $\mathrm{O}$ eu-lírico incorpora tal ideologia, age em conformidade com ela. Essa seria uma interpretação a partir do denominado pequeno tempo.

No entanto, vimos mais acima as reflexões bakhtinianas quanto às possibilidades de interpretação de um discurso, pois cada leitor vai construir sentidos por meio de aproximações dialógicas e valorativas com outros discursos, ainda mais se tal leitor estiver distanciado cultural e historicamente do chamado pequeno tempo: "A interpretação como correlacionamento com outros textos e reapreciação em um novo contexto (no meu, no atual, no futuro).” (BAKHTIN, 2017, p. 67).

O distanciamento, conforme já citado, é fonte de sentidos. O leitor extralocalizado, distanciado, carrega consigo toda outra bagagem cultural, toda uma evolução social, novas valorações. É deste lugar, agora, que pode fazer sua interpretação através de relações dialógicas, de aproximações tensas de discursos outros. Ora, voltemos ao poema precisamente no momento em que o eu-lírico entra no quarto. Fazendo-nos este leitor distanciado, é bastante possível que nossa avaliação mude ao considerarmos o grande tempo. Vejamos como.

Do século XIX até a atualidade, a mulher vem conquistando espaço de voz e de atuação. Inferiorizada historicamente por ideologias machistas em várias esferas, desde a domiciliar, passando pelas esferas educacionais, religiosas e políticas, eram continuamente subvalorizadas numa cultura dominada pelo gênero masculino e seus valores. Alguns fatos históricos contribuíram para o rompimento (ou pelo menos o seu início) da submissão feminina. Dentre eles, citamos o avanço do capitalismo enquanto forma de organização econômica no ocidente, que possibilitou às mulheres serem assalariadas assim como os homens, mesmo com disparidades de valores para a mesma atividade. Tal condição permitiu, de certa forma, um lugar mais independente da mulher na sociedade. Sucederam-se a luta pelo direito 
Linha D’Água (Online), São Paulo, v. 33, n. 3, p. 153-174, set.-dez. 2020

ao voto (no Brasil, em 1932), pela igualdade de salários, por direitos trabalhistas. Destacam-se o movimento feminista (desde o início do século XIX na Europa), a liberdade sexual (com o avanço de métodos contraceptivos). No entanto, presenças da dominação masculina ainda persistem. Há um número expressivo de mulheres do mundo inteiro que sofre violência doméstica, por exemplo. Como uma resposta a tal fato, foi criada no Brasil a Lei Maria da Penha, sancionada em 7 de agosto de 2006. Assim, por meio dessa brevíssima contextualização, visto não ser nossa meta pormenorizar a conquista do espaço feminino na atualidade, pretendemos evidenciar a mudança de horizonte ideológico que experienciamos.

Tal é o cenário favorecido pelo grande tempo em atuação quando interpretamos uma obra nos dias de hoje. Novamente, o leitor distanciado lê um discurso a partir de outra cultura, de outro contexto ideológico. As palavras, nesse novo âmbito, mostram renovados sentidos justamente porque não estão cristalizadas no pequeno tempo. Volóchinov (2017, p. 214) nos apoia: "Em cada época de sua existência histórica, a obra deve interagir estreitamente com a ideologia do cotidiano em transformação, preencher-se por ela e nutrir-se de sua seiva nova."

E é a partir de nova ideologia que nosso apaixonado poeta pode ser avaliado ao entrar no quarto da fada-lavadeira. Poderíamos indagar: com que permissão ele o faz? Como avaliamos a entrada na casa sem ser autorizado, ainda mais furtivamente, enquanto ela dormia? Muito provavelmente como uma invasão. $\mathrm{O}$ poeta, concebido por esse novo olhar, assume outro sentido, pois passa de um homem apaixonado, na visão ultrarromântica, para um intruso. Vimos que as palavras não se engessam em significados, mas alteram-se semanticamente de acordo com a situação concreta do discurso: "A pluralidade de significações é uma propriedade constitutiva da palavra. [...] A sua significação é inseparável da situação concreta de sua realização. Essa significação altera-se em conformidade com a mudança de situação." (VOLÓCHINOV, 2017, p. 230). Logo, todo o poema de Azevedo pode ser lido de outra forma. A atmosfera romântica pode ser desfeita pelo deslocamento do leitor. É o seu olhar, olhar habitado por outros discursos, veiculadores de outras ideologias, o motivo de interpretações diversas de uma obra.

Atualmente, os grupos sociais alvos de preconceitos têm mais voz, não aceitam mais abusos de poder de parcelas ideologicamente opressoras. Há todo um 
Linha D’Água (Online), São Paulo, v. 33, n. 3, p. 153-174, set.-dez. 2020

apoio em discursos de valorização da diferença e do respeito ao ser humano, propagado por entidades representativas e também por universidades e instituições científicas. Logo, contra o discurso que argumentaria "mas se trata de um poema!", diríamos que mesmo na apreciação de obras de arte há influências de posições ideológicas acompanhadas de valorações. Se cultural, histórica e socialmente a mulher sofria (e ainda sofre) preconceitos, hoje, ao menos, há discursos de defesa e de valorização do feminino.

Assim como sinalizamos na análise anterior, não é o caso aqui de apagarmos as vozes interpretativas do poema. Os sentidos não se sobrepõem, mas revelam-se em interação tensa, dialógica. O leitor, ao lidar com os diferentes sentidos da obra, tanto em termos de pequeno ou de grande tempo, tem uma visão mais rica do mundo.

Ao finalizarmos as análises, percebemos o quanto a aplicação de conceitos bakhtinianos auxilia na descrição e explicação de sentidos. Em ambos discursos analisados percebemos uma resposta dialogicamente construída. A postagem do Facebook nasce como uma resposta ao discurso repressor do prefeito carioca, enquanto o poema de Azevedo encarna uma resposta à tensão entre um mundo ideal e outro real. Simultaneamente, em cada discurso emergem tensões entre sentidos ancorados no pequeno tempo e aqueles apoiados no grande tempo, possibilitados pelo distanciamento cultural, social, histórico e ideológico do leitor. A interpretação do discurso, em termos de compreensão responsiva ativa, ganha contornos específicos, avaliações distintas, motivadas pelas relações feitas com outros discursos.

\section{Algumas considerações aparentemente finais}

Segundo o Círculo de Bakhtin, os enunciados são sempre inconclusos, justamente por sua natureza dialógica, de serem respostas a outros enunciados e de esperarem também uma resposta de enunciados vindouros, e com eles travarem relações de sentido. É dessa perspectiva que fazemos, então, um fechamento aparente deste trabalho.

Para tanto, retomamos nossos objetivos, mas por ordem inversa: iniciamos pelos mais específicos e chegamos ao mais amplo. O terceiro era analisar como o distanciamento ideológico sócio-histórico e cultural colaborava para a construção 
Linha D’Água (Online), São Paulo, v. 33, n. 3, p. 153-174, set.-dez. 2020

de novos sentidos. Vimos que tal distanciamento é dado pelas novas perspectivas ideológicas sobre o mundo que autorizam o leitor a fazer interpretações distintas de um "mesmo" objeto. É o distanciamento que permite ao leitor enxergar nas palavras sentidos até então latentes, até mesmo eclipsados para o autor da obra: "Cada palavra (cada signo) do texto leva para além dos seus limites. Toda interpretação é o correlacionamento de dado texto com outros textos" (BAKHTIN, 2017, p. 66). Vemos, nessa citação, uma retomada do conceito de compreensão responsiva ativa, segundo o qual a construção de sentido se dá dialogicamente. Interpretar é dialogar com o outro.

O segundo objetivo versava sobre a discussão da importância do conhecimento do contexto cultural de produção do discurso para a sua interpretação. Ora, procuramos mostrar nas análises que o resgate do contexto no qual a obra foi concebida tem seu valor, pois é a partir dele que o discurso se constituiu como uma reposta a outros discursos. No entanto, mostramos que as obras não se fixam no tempo. Recorrendo novamente a Bakhtin, as obras morreriam se permanecessem encerradas em sua época de produção, perderiam seu sentido, permaneceriam estagnadas no passado e muito provavelmente seriam apagadas da nossa memória cultural.

Nesse caminho chegamos ao primeiro objetivo, refletir sobre o conceito de grande tempo aplicado à interpretação. Bakhtin viu neste conceito a explicação de as obras apresentarem-se sempre renovadas ao longo das épocas, no sentido fazerem sentido àqueles que as leem. Embasado na significação sempre aberta das palavras, concluiu que as obras revelam sentidos ao entrarem no grande tempo, quer dizer, ao dialogarem com outros discursos situados em outras posições ideológicas, todos articulados pelo leitor. Citamos o autor russo mais uma vez: "Um texto só tem vida contatando com outro texto (contexto). Só no ponto desse contato de textos eclode a luz que ilumina retrospectiva e prospectivamente, fazendo dado texto comungar no diálogo.” (BAKHTIN, 2017, p. 67). Assim, os discursos revelam continuamente sua vida. 
Linha D’Água (Online), São Paulo, v. 33, n. 3, p. 153-174, set.-dez. 2020

\section{Referências}

AZEVEDO, A. de. Lira dos vinte anos. Porto Alegre: L\&PM, 1998.

BAKHTIN, M. Notas sobre literatura, cultura e ciências humanas. Tradução Paulo Bezerra. São Paulo: 34, 2017.

BEZERRA, P. Bakhtin: remate final. In: BAKHTIN, M. Notas sobre literatura, cultura e ciências bumanas. São Paulo: 34, 2017, p. 81-96.

BOSI, A. História concisa da literatura brasileira. São Paulo: Cultrix, 2002.

BRANCA de neve e os sete anões. Provedor Disney Brasil. Direção David Hand, 1965. 1 vídeo (1:23:57). Disponível em: https://www.youtube.com/watch?v=5UdE4Q-Agag. Acesso em 19 jun. 2020 .

GOETHE, J.W. Os sofrimentos do jovem Werther. Tradução Marion Fleischer. Prefácio J.F. Angelloz. 2.Ed. São Paulo: Martins Fontes, 1998.

SHAKESPEARE, W. Othelo, o Mouro de Veneza. Tradução D. Luiz de Bragança.Porto: Lello, 1906.

VINGADORES, A CRUZADA DAS CRIANÇAS. Allan Heinberg e Jim Cheung. São Paulo: Salvat, 2016.

VOLÓCHINOV, V. Marxismo e filosofia da linguagem: problemas fundamentais do método sociológico na ciência da linguagem. Tradução Sheila Grillo e Ekaterina Vólkova Américo. São Paulo: 34, 2017.

Recebido: 20/06/2020.

Aprovado: 23/07/2020.

DELANOY, C. P. 0 conceito de grande tempo e interpretaccão de discursos 